\section{Um arranjo produtivo local sob a perspectiva da teoria da regulação cultural: 0 caso do Porto Digital englobando o Portomídia}

\author{
A local productive arrangement from the perspective of cultural regulation \\ theory: the case of Porto Digital encompassing Portomídia
}

Revista Organizações \& Sociedade 2020, 27(93), 292-313

(C) Autor(es) 2020

DOI 10.1590/1984-9270937

ISSN 1984-9230

www.revistaoes.ufba.br

NPGA, Escola de Administração

Universidade Federal da Bahia

Recebido: 01/02/2018

Aprovado: 01/08/2019

a Universidade Federal Rural de Pernambuco, Recife, PE, Brasil

b Universidade Federal de Pernambuco, Recife, PE, Brasil

\title{
Resumo
}

Este estudo objetiva desvelar o modo como ocorre o processo de regulação cultural na ampliação do núcleo de tecnologia da informação e comunicação Porto Digital, domiciliando um polo de economia criativa denominado Portomídia Centro de Empreendedorismo e Tecnologia da Economia Criativa. Sob o prisma dos estudos culturais, a partir da teoria da regulação cultural, buscamos compreender os significados articulados para a expansão do escopo de atuação desse sistema tecnológico. Desenvolvemos um estudo de caso incorporado para avaliar o arranjo produtivo local Porto Digital a partir de diferentes níveis ou unidades de análise, envolvendo apreciações sobre a regulação cultural nos âmbitos do poder institucional, econômico e subjetivo. Essas categorias analíticas fundamentaram as análises que contemplam a ideia da influência do poder econômico (sistema de classes) e do poder institucional (regras e regulação) na (re)configuração dessa aglomeração de empresas intensivas em criatividade. Por sua vez, o poder subjetivo se manifesta no ato empreendedor como ação política fundamental para a expansão do polo criativo.

Palavras-chave: Regulação Cultural; Arranjo Produtivo Local; Porto Digital; Portomídia.

\section{Abstract}

This study describes how the process of cultural regulation occurs in the expansion of the center for information and communication technology Porto Digital, turning local a pole of creative economy called Portomídia - Center of Entrepreneurship and Technology of the Creative Economy. Under the prism of cultural studies, based on cultural regulation theory, we analyze the present articulated meanings to expand the scope of this technological system. We developed an embedded case study to evaluate the local productive arrangement Porto Digital with different levels or units of analysis involving assessments on cultural regulation in the areas of institutional, economic and subjective power. These analytical categories were based on the analysis of the influence of economic power (class system) and institutional power (rules and regulations) on the configuration of this cluster of creativity-intensive enterprises. In turn, subjective power manifests itself in the entrepreneurial act as a fundamental political action for the expansion of the creative pole.

Keywords: Cultural Regulation; Local Productive Arrangement; Porto Digital; Portomídia. 


\section{Introdução}

A regulação das atividades econômica e política tem um caráter fragmentário e instaura processos que reconfiguram os lugares para atender às novas demandas de circulação e formação de novos negócios. Nesse movimento, observamos certas infraestruturas-chave compondo espaços locais que formam uma nova totalidade global (Hallam \& Ingold, 2008; Liefooghe, 2015; "Relatório de", 2012). Nesse cenário controverso, a regulação auxilia no [re]desenho dos contornos dos lugares, que passam a contar com o suporte de um conjunto de equipamentos, a exemplo dos parques científicos e tecnológicos (PqTs). Eles funcionam como focos de interesse e investimento de governos e empresas recorrentes nas últimas três décadas, devido a sua atuação como agências potencializadoras de inovação e representando loci de desenvolvimento socioeconômico e cultural.

Conhecidos como habitats de inovação e empreendedorismo, os PqTs, como o Porto Digital - domiciliado na cidade do Recife (PE) -, constituem iniciativas pavimentadas por mecanismos de infraestrutura e serviços especializados em que se visa o desenvolvimento tecnológico e econômico de determinado local com base na dinamização da atividade empresarial e geração de emprego e renda, indo até a configuração de cidades inteligentes (smart cities) (DattaGupta, 2014). Como forma de manter as características de inovação do empreendimento, os PqTs desenvolvem esforços permanentes para atrair empresas e setores inovadores a fim de expandirem e consolidarem seus negócios (Minguillo, Tijssen, \& Thelwall, 2015). No Brasil, existem em torno de 94 PqTs distribuídos em todo o território nacional, por meio dos quais são gerados cerca de 30 mil empregos, distribuídos em 939 empresas mantidas em atividade. Foram registrados investimentos da ordem de 5,8 bilhões de reais em recursos federais, estaduais e municipais revertidos na operacionalização desses PqTs (Associação Nacional de Entidades Promotoras de Empreendimentos Inovadores - Anprotec, 2014).

0 arranjo produtivo local (APL) urbano Porto Digital está sob o marco de um processo regulatório de fomento a atividades de negócios e desenvolvimento tecnológico (softwares) do ramo da economia criativa. Representa uma associação de vários atores governamentais, acadêmicos e empresários que conseguiram mobilizar recursos, conhecimento e arcabouços institucionais para estruturar uma plataforma inovadora na área de tecnologias da informação e comunicação (TIC) e se colocam como variável estruturante das outras cadeias produtivas presentes no estado e no país. Recentemente, ampliou o seu escopo de atuação e âmbito de abrangência territorial ao incorporar setores intensivos em atividades criativas no equipamento cultural denominado Portomídia - Centro de Empreendedorismo e Tecnologia da Economia Criativa.

O Portomídia busca aliar conhecimento e recursos de infraestrutura para mover a criação de seus respectivos artefatos culturais. Esse polo é pautado por temáticas que visam o desenvolvimento regional, quais sejam: a educação (por meio da capacitação e da qualificação prática); a experimentação (tecnologia de ponta para suporte à criação por meio dos estúdios e laboratórios); o empreendedorismo (incubação, formação empreendedora e funding); e, por fim, a exibição (galeria de artes digitais, com foco permanente na produção local) (Cictec, 2013; Porto Digital, 2013).

As pesquisas de referência com respeito a APL de alta tecnologia produzidas por instituições como a Organização para a Cooperação e Desenvolvimento Econômico e a International Association of Science Parks (IASP) veem os arranjos produtivos como soluções inovadoras para problemas econômicos e para ganho de competitividade dos setores industriais. Estatísticas são desenvolvidas e surveys são aplicadas nas empresas que fazem parte do parque para produzir indicadores que servirão de base para a ação dos reguladores e para a formulação de políticas públicas. Isso tudo com o suporte de acadêmicos, consultores que confeccionam modelos de gestão inovadores para guiar as políticas dos arranjos produtivos. Ou seja, trazem uma abordagem economicista, legal e administrativa que põe luz tão somente sobre partes do fenômeno, conforme corroboram os estudos de Steiner, Cassim e Robazzi (2008), Gargione (2011) e Figlioli e Porto (2012).

A abordagem economicista versa sobre as discussões teóricas em torno das perspectivas de mercado, em que são apresentadas visões da economia evolucionária, preconizadas pela escola austríaca e por protagonistas do 
debate referente a esse tema advindo da sociologia econômica moderna (Bauman, 1999; Hardt \& Negri, 2006; Meirelles, 2010). Esse raciocínio demarcado apenas por uma base econômica prescritiva se revela insuficiente para ampliar o entendimento com respeito a espaços de conflitos, tensões e disputas presentes nesses tipos de aglomerações produtivas.

Por outro lado, nossa proposta reside em avançar com referência à análise de formas de entendimento de práticas regulatórias vigentes em PqTs que vão além das formulações teóricas advindas de autores como Ipiranga, Faria e Amorim (2008), que trazem uma leitura dos arranjos produtivos a partir dos relatos subjetivos dos atores inseridos nesses espaços, Correia \& Gomes (2012), que privilegiaram unicamente uma análise no nível meso, analisando as articulações e ações institucionais das principais organizações inseridas no que chamaram de habitats de inovação, Lacerda \& Fernandes (2015), que trazem essencialmente as disputas de classe em torno dos PqTs evidenciando o componente imobiliário do Projeto Porto Digital, que acaba inibindo o cumprimento da função social desse espaço da cidade do Recife, e Vásquez-Urriago, Barge-Gil e Rico (2016), que ficaram no nível de análise da firma para avaliar os ganhos de inovação das empresas inseridas em práticas colaborativas em PqTs. Nesse estudo, calcados na abordagem da regulação cultural, pretendemos colocar luz sobre as práticas sociais de um PqT a partir de diferentes níveis de análise nos âmbitos do poder econômico (sistema de classes), poder institucional (regras e regulação) e poder subjetivo que se manifesta no ato empreendedor como ação política fundamental para a expansão do polo criativo.

O objetivo do estudo consiste em desvelar o modo como os protagonistas de estruturas de poder vigentes num PqT atuam entre diferentes grupos de atores que condicionam os processos de regulação econômica, política e social na expansão de um conglomerado produtivo composto de empresas do setor de TIC, domiciliadas na Região Metropolitana do Recife. Certa literatura organizacional acerca dos APL situados no Brasil não contempla de forma plena os elementos coletivos da vida econômica e o horizonte conceitual simbólico dessas organizações. Desse modo, o debate deste estudo se mostra pertinente na cobertura do hiato conceitual relativo ao processo de regulação cultural presente no universo dos parques de tecnologia intensiva.

As estruturas organizacionais contemporâneas são influenciadas por uma complexa dinâmica de parcerias e estão imbricadas no universo rizomático de entidades imersas no advento da globalização cultural (Link, 2009; Rodríguez-Pose \& Hardy, 2014; Thompson, 1997; Thorpe, 2008). Dessa maneira, os discursos e práticas que traduzem as estratégias traçadas pelas principais lideranças do Porto Digital voltadas para viabilizar esse empreendimento serão analisados pela lente teórica da regulação cultural, inspirada nos estudos culturais (EC).

Os EC são uma resposta à crescente complexidade dos fenômenos sociais, tendo sido originados no Centre for Contemporary Cultural Studies (CCCS, do inglês Centro para Estudos Culturais Contemporâneos) de Birmingham, com rápida ascensão mundial a partir dos anos 1980. Da mesma forma que autores como Williams (1974) descrevem a experiência da recepção como fenômeno complexo, multidimensional e portador de múltiplos significados, a discussão do fenômeno regulação o vê como uma prática cultural articulada em meio às complexidades da relação entre economia, política e sociedade. Todos esses campos auxiliam o entendimento de um contexto cultural como sendo o resultado contingencial de uma variedade de influências que se sobredeterminam (Escosteguy, 2018; Thompson, 1997).

A abordagem da regulação cultural está desdobrada em três categorias analíticas de poder: institucional, econômica e subjetiva (Foucault, 2014; Thompson, 1997). Essas categorias constituem lentes conceituais para a inserção no campo estudado, por meio de um recorte de estudo de caso qualitativo que se vale de entrevistas semiestruturadas com atores-chave, cujas narrativas possibilitam o entendimento do processo de expansão do PqT Porto Digital, englobando o recém-criado Portomídia. Tendo como pano de fundo essa discussão, o interesse na elaboração do presente estudo reside em buscar compreender: Como ocorreu o processo de regulação cultural na expansão do escopo de atuação do APL Porto Digital que culminou na criação do polo de economia criativa Portomídia? 


\section{0 circuito da cultura emergente dos EC}

Os EC representam uma abordagem multidisciplinar envolvendo áreas do conhecimento como estudos literários, sociologia, comunicação e linguística, as quais se voltam para os modos de produção e geração de significados na sociedade contemporânea (Mattelart \& Neveu, 2004). Essa abordagem é decorrente dos estudos de pesquisadores como Richard Hoggart, Raymond Williams, Edward Palmer Thompson, Stuart Hall e Richard Johnson que integravam o CCCS na Universidade de Birmingham (Escosteguy, 2013, 2018).

A abertura conceitual e a versatilidade teórica dos EC permitem pensá-los como construção discursiva que disponibiliza um conjunto de opções teóricas não reduzidas ao pluralismo simplista ou à ausência de teoria. Pelo contrário, nos EC já existem engajamentos com a teoria da regulação cultural, tais como o entendimento pós-estruturalista do tema como sendo uma interseção complexa de múltiplas posições do sujeito; a ênfase antiessencialista nas questões identitárias que passam a ser reconhecidas como tendo sido construídas em meio a relacionamentos dinâmicos; a base pós-colonial centrada no hibridismo e no "terceiro-espaço" que desestabiliza a divisão entre uniformidade e diferença; a noção derrideana do significante de que é determinado por um contexto que nunca é totalmente fixo e, portanto, nunca totalmente capturado, e a noção focaultiana de poder e saber como sendo dispersos e capilarizados. Logo, todas essas perspectivas teórico-críticas contribuem para a concepção da teoria da "cultura" presente nos EC como sendo algo sempre em processo, sobredeterminado por uma multiplicidade de forças diversas e inter-relacionadas, além do fato de não estarem reduzidas a uma única origem. Tais estudiosos se colocam diante do esforço de entender a cultura e suas regulações como formas de expressão de poder nas atividades cotidianas das formações sociais.

No campo organizacional, certas perspectivas teóricas e práticas vigentes tendem a reduzir o papel da cultura que, conforme argumentam Payne (2015) e Whelan (2016), é tratada como um mero construto manipulável, utilizado para incrementar os resultados organizacionais. Tal perspectiva despreza as relações de poder existentes e não considera a força política dos indivíduos que as compõem. Dessa maneira, parece fundamental descortinar determinadas abordagens acerca da complexidade da cultura na vida cotidiana.

Em contraponto a uma construção conceitual determinista e reducionista de cultura, a proposta teórico-metodológica dos EC sugere o modelo teórico do circuito de cultura de Du Gay, Hall, Janes, Mackay e Negus (2013), alicerçado nas cinco dimensões culturais de produção, consumo, identidade, representação e regulação. Esse modelo enfatiza as mudanças econômicas, políticas e sociais que se viabilizam no plano das significações vigente nas práticas institucionalizadas (Ho, 2016). Assim, essa abordagem se revela apropriada como guia para o entendimento da dinâmica multifacetada de regulação cultural vigente no âmbito dos PqTs.

Os significados conferidos a determinada prática social podem orbitar em torno dessas categorias analíticas, ou seja, eles poderão ser diversos e conflitantes, especialmente quando se trata de entender as dinâmicas interativas de articulação em redes organizacionais de modo a garantir um processo de inovação e desenvolvimento profícuo para seus articuladores. Logo, Johnson (2007) reconhece que os significados múltiplos atribuídos a determinada ação, ao longo do circuito da cultura, revelam as lutas políticas estabelecidas no âmbito dessas interações. A contribuição de Johnson se alinha com os aportes de Sergeeva (2016) que, ao analisar a forma como a identidade dos "campeões de inovação" do setor de construção civil do Reino Unido é formulada, destaca que as inovações de maior êxito são aquelas capazes de construir narrativas que perpassassem tanto as equivalências de interesse dos grupos de colaboração como os impasses oriundos das disputas de grupos divergentes. Portanto, a autora mapeia a dinâmica política que estrutura essas redes com base numa perspectiva de um conjunto de identidades coletivas, uma vez que as propriedades estruturais das redes de colaboração setorial apresentam limites conceituais quando tratadas de forma atomizada.

No modelo teórico sugerido por Du Gay et al. (2013), o contexto também é destacado como fator relevante para se interpretar o processo de significação. A concepção integradora do circuito considera as contingências das circunstâncias de produção, circulação e consumo. Por isso, os significados que convencionalmente são atribuídos ao produto cultural estão situados em momentos sócio-históricos particulares (Almeida, 2012). A ideia do circuito 
da cultura apresenta a possibilidade de se investigar o processo de construção de significados culturais em diferentes contextos de negociação. Isso ocorre em espaços de transferência de conhecimento, a exemplo dos PqTs, revelando uma arquitetura jurídica-institucional específica, decorrente de um contexto dinâmico e característico de uma negociação contínua com a finalidade de convergir interesses divergentes para objetivos consensuais, em decorrência da necessidade dos seus grupos de operacionalizar projetos inovadores compartilháveis.

A regulação

A regulação da cultura diz respeito a práticas sociais de determinada sociedade moldadas e sistematizadas no âmbito cultural. A regulação cultural aponta para os aspectos performativos e produtivos da cultura pública. Ou seja, isso traz, ao mesmo tempo, os limites do poder estatal e a força necessária para que o governo legitime suas intervenções públicas, mesmo quando suas lideranças afirmam que agem pensando no interesse público (Ayeni, 2018; Kaur \& Mazzarella, 2009). Para pesquisadores como Motta e Alcadipani (2004) e Butler (2014), a abordagem da regulação desenvolvida por Foucault (2014) é dinâmica e frutífera porque tem como foco a compreensão dos discursos políticos e das práticas sociais vigentes na modernidade. Logo, a visão de poder presente no pensamento foucaultiano rompe com a concepção de que tal poder se encontra centralizado na figura do Estado ou de outras categorias sociais abstratas (i.e., classes sociais, religião). Foucault nos apresenta o conceito do poder microfísico, diluído no interior das redes sociais que servem para regular os saberes, os discursos e as normas, intermediando as relações entre pessoas no cotidiano social (Brígido, 2013).

Foucault (2014) vislumbra o desenvolvimento da ordem moderna das coisas como um movimento de regimes externos à autodisciplina, em que o poder deixa de ser exclusividade do campo político e do aparelho estatal se deslocando para as micropráticas da vida social e se materializa numa gama extensa de relações pessoais, estruturando e reproduzindo as normas institucionalizadas (Šupa, 2015).

A descrição de Weber (2013) com respeito à modernidade é caracterizada pela crescente racionalização do mundo da vida, em que o indivíduo está subjugado menos pela força do que por uma espécie de contrato voluntário, como posteriormente descreve Foucault (2016). A diferença fundamental entre esses autores reside no fato de que, enquanto Weber constata as racionalidades formais e as regulações (institucionais), Foucault destaca um aspecto mais amplo de discursos e práticas de controle que tanto empoderam o sujeito como regulam o seu comportamento. As posições de fala, escrita, as ideias e leis vigentes, além das formas de discurso associadas às redes de relacionamento, são também elementos pelos quais reconhecemos os indivíduos como sujeitos separados que possuem direitos e necessidades específicas.

Com base no argumento de Michel Foucault em torno das práticas regulatórias, existem, então, três tipos de poder subjacentes à dinâmica da regulação cultural, quais sejam: poder institucional, exercido por meio de regras e regulação; poder econômico, que funciona como um sistema de classes; e poder subjetivo, que trata o indivíduo como agente que luta contra os discursos já organizados em torno de si (Thompson, 1997).

O poder institucional é estabelecido por meio das normas disciplinares e biopolíticas e compõe estruturas formais ou instituições regulatórias, tais como a fábrica, a escola, os presídios e outras instituições vinculadas ao Estado. Em se tratando das normas, o conceito desse tipo de poder revela um sentido mais amplo, conforme seu caráter exclusivamente jurídico, a exemplo das leis. Logo, a norma tem mais a ver como um princípio de exclusão ou de incorporação relativa à(s) prática(s) do(s) indivíduo(s). Na abrangência do conceito de norma, são incorporadas aquelas relacionadas ao comportamento do(s) indivíduo(s), às normas sociais que regulam os saberes e às normas de conduta (Fonseca, 2010; Foucault, 2014; Thompson, 1997).

O poder econômico é estabelecido com base no sistema de classes. Foucault (2014) reconhece que por trás de um poder estatal existe uma classe dominante. Dessa maneira, num sistema de classes, o poder político é praticado em uma pluralidade de núcleos e pontos de apoio invisíveis e desconhecidos. Para tanto, ele exemplifica essa demarcação de instâncias normativas ao constatar que uma instituição de ensino, como 
a universidade na condição de sistema de educação superior, não é constituída tão somente para disseminar o conhecimento. Essas entidades de formação e difusão do conhecimento "são feitas para manter certa classe social no poder, e para excluir os instrumentos de poder de outra classe" (p. 71).

Por fim, tem-se o poder subjetivo, em que o indivíduo luta contra discursos e práticas organizados em torno de si mesmo (Chomsky \& Foucault, 1971; Foucault, 2014; Hall, 2016; Rose, 2011; Thompson, 1997). 0 poder aqui é equivalente ao self, que deve ser um ente subjetivo e aspirar à autonomia, buscar a realização pessoal, avaliar sua realidade e destino na condição de responsabilidade individual, além de gerar significado com base nos projetos pessoais e moldagem do seu cotidiano por meio de escolhas subjetivas. Tais modos de refletir a respeito dos seres humanos no status de selfs e essas maneiras de julgá-los estão atrelados a determinadas formas de agir com respeito a esses selfs. Nesse caso, representam selfs regulados pelas lógicas do neoliberalismo ao realizarem suas reformas da política macro e microeconômica, cultura organizacional, bem-estar social e responsabilidade dos cidadãos (Ayeni, 2018; Malik, Chapain, \& Comunian, 2017; Silkenbeumer, Schiller, Holodynski, \& Kärtner, 2016; Thompson, 2015). Portanto, essas mudanças concentram-se em questões atreladas a pós-modernização, globalização e pós-Fordismo (Hall, 2016; Rose, 2011).

As noções sobre subjetividade variam amplamente de cultura para cultura, e existem formas de explicar tais variações, relacionando concepções sobre a subjetividade tanto como práticas religiosas, legais e penais quanto com estruturas mais amplas nas esferas social, política e econômica (Rose, 2011). Rose discorre sobre a relação entre poder e subjetividade:

Nós, frequentemente, pensamos em poder em termos de restrições que dominam, negam, e reprimem a subjetividade. Foucault, entretanto, analisa o poder não como uma negação da vitalidade e das capacidades dos indivíduos, mas como a criação, modelagem e utilização dos seres humanos como sujeitos. Poder, em outras palavras, trabalha através, e não contra a subjetividade. (p. 211)

Em suma, Foucault (2016) afirma que o rumo do desenvolvimento da modernidade se evidencia a partir da articulação que se projeta desde os poderes institucional e econômico até o poder subjetivo, que se tornam objeto, alvo e recurso essenciais à efetivação de certas estratégias e táticas de regulação. Logo, essa lógica de compreensão concerne ao debate referente a práticas de regulação e disciplina externa, fundamentais à garantia e aclaramento de fenômenos de interação social, como ocorre no cerne do Porto Digital, em que são desenvolvidas práticas empreendedoras que induzem à revisão de marcos institucionais estruturados sob a égide das iniciativas dos gestores que detém liderança do território.

O conceito de poder subjetivo permite uma nova forma de olhar para o sujeito empreendedor na qualidade de ator político inserido num campo de articulações institucionais (Bresnen, 2015; Mangematin, Sapsed, \& Schüßler, 2014; Mello \& Cordeiro, 2010). O esforço teórico dos autores representa a emergência de uma solução para se pensar as práticas sociais a partir das condições definidas pela estrutura de articulação política de determinado grupo de poder. Logo, essa interação trata do envolvimento entre práticas e estruturas contemplando os atores sociais operando em meio a disputas e tensões que definem lógicas distintas de dominação (Hall, 2018). Sob essa compreensão, as ações protagonizadas por uma liderança transformacional são oportunidade para a introdução de novas práticas empreendedoras em setores, como a indústria criativa, que desafiam as convenções institucionalizadas em decorrência de determinados interesses no campo organizacional (Mangematin et al., 2014; Parrilli, Nadvi, \& Yeung, 2016).

A reconfiguração acerca do olhar sobre as disputas políticas de atores estratégicos em espaços de tensão econômica pode ser dirigida por determinados interesses, cujos portadores conseguem alcançar certas posições sociopolíticas por meio de soluções negociadas e contingentes. Portanto, o esforço sistemático por compreender esses espaços de disputa, como o APL Porto Digital, torna-se chave no discernimento das 
tensões a respeito desse tipo de arranjo institucional, uma vez que, por si só, nem a determinação estrutural, nem a leitura unicamente pautada nas forças do mercado podem fornecer os caminhos para tal entendimento.

\section{Contextualizando o caso: o Porto Digital englobando o Portomídia}

O APL Porto Digital surge da articulação empreendedora de vários atores, entre os quais temos: o Governo de Pernambuco, o Centro de Estudos e Sistemas Avançados do Recife (C.E.S.A.R.), o Centro de Informática da Universidade Federal de Pernambuco (CIn/UFPE), que criaram instrumentos e implantaram ações para estruturar e consolidar um sistema local de inovação na área de TIC, articulado com outros polos dinâmicos e inserido nas cadeias produtivas dos setores industriais e de serviços (Corrêa, 2007; Silva, 2012).

Em 2011, por meio da Lei Municipal do Recife n 17.762, o Porto Digital anunciou a sua expansão territorial para um quadrilátero no bairro de Santo Amaro, assim como obteve a concessão de um programa de benefícios fiscais aos estabelecimentos que se instalassem no Arranjo. A partir dessa normativa, o Parque expandiu o seu escopo de atuação ao incorporar atividades características da economia criativa no seu portfólio de produtos e serviços tecnológicos advindos de áreas como multimídia, games, cinema, design, música e fotografia (Porto Digital, 2013; Cictec, 2013).

A estratégia de expansão do Porto Digital se soma a um conjunto de iniciativas que vêm se potencializando na cidade do Recife ao longo das últimas décadas, cuja finalidade, nos termos de Oliveira (2003) e Lacerda e Fernandes (2015), consiste no desenvolvimento e na dinamização da economia regional. Acrescenta-se a essas iniciativas a realização da pesquisa Inovações tecnológicas e cadeias produtivas selecionadas: Oportunidades de negócios para o município de Recife (PE), realizada pelo Centro de Gestão e Estudos Estratégicos (CGEE) (2011), que teve como objetivo principal contribuir para o estabelecimento de uma nova dinâmica produtiva no horizonte da economia local, com suporte de mecanismos de desenvolvimento da inovação tecnológica nas principais cadeias produtivas da cidade do Recife. Essas iniciativas contam com a articulação de atores-chave que mobilizam as estruturas organizacionais e os arcabouços institucionais para a atração de recursos fundamentais na busca por atender as suas demandas com respeito a projetos futuros dos empreendimentos que lideram.

\section{Trilhas de investigação}

A natureza do estudo é qualitativa por ser adequado à compreensão do modo como funcionam as possíveis tensões emergentes no processo de regulação cultural em meio ao movimento de expansão de um PqT (Denzin, 2009; Denzin \& Lincoln, 2006).

Quanto à estratégia de investigação, desenvolvemos um estudo de caso incorporado, compreendido num sentido amplo, conforme descreve Creswell (2010), apropriado para a averiguação de algum programa, evento, atividade ou processo que envolva um ou mais indivíduos. Esse tipo de estudo permite a avaliação do APL Porto Digital a partir de diferentes níveis ou unidades de análise ao envolver apreciações referentes à regulação cultural nos âmbitos institucional, econômico e subjetivo (Martins, 2008).

0 método de estudo de caso é pertinente quando no interior de determinado caso único são consideradas várias de suas subunidades (Stake, 2005). Portanto, o APL Porto Digital é visto aqui sob a perspectiva de sua ampliação ao ser contemplada sua nova unidade produtiva, denominada Portomídia, portando como subunidades as lideranças que atuam no desenvolvimento de atividades de Economia criativa, a exemplo de associações empresariais e órgãos públicos.

O APL Porto Digital constitui um caso elucidativo desta discussão, uma vez que se trata de um aglomerado de empresas de TIC que demarcam uma atmosfera de inovações, e, ao longo dos anos, tem conseguido se materializar como espaço de geração de negócios intensivos em tecnologia. Os frutos econômicos 
desse cluster são consequência da ação das lideranças locais que não cessam de articular suas demandas junto a instituições paraestatais, universidades e órgãos governamentais (Corrêa, 2007). Desse modo, o entendimento das condições contextuais é pertinente para se compreender o fenômeno estudado no que tange ao processo de regulação cultural.

Em se tratando da construção do plano de coleta de dados e do corpus da pesquisa, optamos pelo método de entrevistas individuais por ser considerado significativo para atingir o entendimento lúcido do caso (Lincoln \& Guba, 1985). As entrevistas semiestruturadas ou semiabertas, conforme demonstrado no Quadro 1 , permitiram uma visão ampla dos acontecimentos que não puderam ser presenciados (Stake, 1999, 2005) e permitiram maior liberdade ao entrevistado, com o entrevistador tecendo comentários complementares às questões centrais do protocolo, que estimularam o interlocutor a elucidar detalhes significativos do fenômeno em pauta.

Quadro 1 - Instituições e empresas pesquisadas no estudo

\begin{tabular}{|c|c|c|c|}
\hline Cód. & $\begin{array}{l}\text { Instituição/ } \\
\text { Empresa }\end{array}$ & Posição & Histórico do entrevistado \\
\hline E1 & CIn/UFPE & Professor & $\begin{array}{l}\text { Professor/pesquisador da UFPE. Fez parte da diretoria do C.E.S.A.R., da } \\
\text { Sociedade Brasileira de Computação e do Conselho de Administração do } \\
\text { Porto Digital. Participou da fundação de empresas instaladas no Porto } \\
\text { Digital, tais como a Meantime Mobile Creations, Jynx Playware e Daccord. }\end{array}$ \\
\hline E2 & Hub Criativo & $\begin{array}{l}\text { Sócio- } \\
\text { fundador }\end{array}$ & $\begin{array}{l}\text { Empreendedor e sócio-fundador da Hub Criativo, uma empresa de } \\
\text { consultoria embarcada no APL Porto Digital. Está envolvido em projetos } \\
\text { como o Fab Lab e Robolivre. }\end{array}$ \\
\hline E3 & Porto Marinho & Fundador & $\begin{array}{l}\text { Doutor em Economia, sócio-fundador da empresa de consultoria } \\
\text { Porto Marinho Ltd. embarcada no Porto Digital, um dos fundadores } \\
\text { e ex-presidente do Porto Digital. Ex-presidente do Fórum Nacional de } \\
\text { Secretários de Ciência e Tecnologia do Brasil, ex-CEO do núcleo Softex } \\
\text { Recife do Programa Nacional Brasileiro de Apoio a Empresas Exportadoras } \\
\text { de Software (Softex 2000), ex-CEO da Agência de Desenvolvimento do } \\
\text { Governo do Estado de Pernambuco. }\end{array}$ \\
\hline E4 & $\begin{array}{l}\text { Instituto Delta } \\
\text { Zero*1 }\end{array}$ & $\begin{array}{l}\text { Conselho } \\
\text { consultivo }\end{array}$ & $\begin{array}{l}\text { Jornalista, ex-diretora executiva do Instituto Delta Zero, uma instituição } \\
\text { que reúne empresários de setores vinculados a economia criativa em } \\
\text { Pernambuco. }\end{array}$ \\
\hline E5 & $\begin{array}{l}\text { Gapuia - } \\
\text { Cultura, } \\
\text { Turismo e } \\
\text { Comunicação*2 }\end{array}$ & $\begin{array}{l}\text { Sócia- } \\
\text { fundadora }\end{array}$ & $\begin{array}{l}\text { Sócia-fundadora da Gapuia. Ex-gestora da Representação Regional } \\
\text { Nordeste do Ministério da Cultura. }\end{array}$ \\
\hline E6 & $\begin{array}{l}\text { Núcleo de } \\
\text { Gestão do Porto } \\
\text { Digital }\end{array}$ & Presidente & $\begin{array}{l}\text { Economista e mestre em engenharia da produção, atual diretor-presidente } \\
\text { do Porto Digital, ex-Secretário de Desenvolvimento Econômico e Turismo } \\
\text { do município do Cabo de Santo Agostinho, ex-diretor comercial da } \\
\text { Empresa Pernambucana de Turismo. É também conselheiro do C.E.S.A.R. }\end{array}$ \\
\hline E7 & SECTEC/PE & Ex-secretário & $\begin{array}{l}\text { Ex-secretário de Ciência, Tecnologia e Desenvolvimento Econômico do } \\
\text { Recife. Ex-secretário de Ciência Tecnologia de Pernambuco. Ex-membro dos } \\
\text { conselhos de administração do Porto Digital e do Instituto de Tecnologia de } \\
\text { Pernambuco. Ex-presidente do Conselho Superior da Fundação de Amparo à } \\
\text { Ciência e Tecnologia do Estado de Pernambuco. Coordenou a representação } \\
\text { do Ministério da Ciência, Tecnologia e Inovação no Nordeste. }\end{array}$ \\
\hline
\end{tabular}

Fonte: Elaborado pelos autores.

1. Nos casos indicados foi realizada apenas uma entrevista, mas procurou-se captar dados referentes a ambas as instituições.

2. A mesma pessoa foi entrevistada sobre o Instituto Delta Zero e a empresa Gapuia. Na época, a entrevistada era conselheira consultiva do Instituto e é sócia-fundadora da Gapuia, e fez questão de responder separadamente sobre cada um, ora como conselheira, ora como sócia fundadora. 
A definição dos sujeitos da pesquisa foi concretizada mediante juízo crítico determinado pelos pesquisadores e diz respeito aos profissionais que trabalham e respondem por cargos de liderança, conforme caracterização no Quadro 1.

As entrevistas foram agendadas com contatos precedentes por meio de ligações telefônicas e emails em dias e horários acordados pelos profissionais. Os relatos dos entrevistados foram registrados e transcritos conforme suas respectivas autorizações. A familiaridade dos pesquisadores com o parque e a ciência da rotina acelerada da maioria dos sujeitos pesquisados tornou possível uma interação mais natural com os interagentes, possibilitando certa acurácia nas informações colhidas.

Em conjunto com essas entrevistas, acessamos documentos oficiais, relatórios, leis e normas, a fim de encontrar dados que contribuíssem para aprofundar a compreensão do caso estudado (Stake, 1999), além de materiais audiovisuais (Creswell, 2010).

Durante a fase de interpretação dos dados, foram realizados procedimentos de triangulação e validação dos resultados das análises, em que buscamos excluir possíveis entendimentos equivocados a respeito do fenômeno (Bauer \& Gaskell, 2002; Stake, 1999). Logo, o estudo contou com análises trianguladas por pesquisadores que compõem o lócus de Investigação em Economia Criativa da UFPE. Essa triangulação de teoria e métodos teve como objetivo garantir a qualidade dos achados submetidos ao escrutínio teórico.

\section{Apresentação e discussão dos resultados}

Os conceitos de poder institucional, econômico e subjetivo constituem tipologias referentes à regulação cultural do arranjo institucional urbano Porto Digital, que incorporou um novo polo, o Portomídia. Devem fornecer os meios de pensarmos de forma "não reducionista" as relações entre os domínios econômico/social e simbólico nesse processo de expansão que não se resigna a um formalismo vazio (Hall, 2018).

0 poder institucional

O poder institucional, que realiza a mediação dos interesses nesse território, se origina da formulação e execução das regras e normas formais ou decorre de ações político-legais advindas de instituições regulatórias (Foucault, 2014), qualificando o papel do Estado como regulador-intervencionista. O Porto Digital, entidade constituída nos termos do poder institucional, é uma organização social (OS) que segue parâmetros estabelecidos pela Lei Estadual no $11.743 / 2000$ e do Decreto Estadual no 23.046/2001, atribuição normativa que reside em qualificar as OS. Além disso, o Decreto Estadual n 40.568/2014 [re] qualifica a titulação da OS "Associação Núcleo de Gestão do Porto Digital (NGPD)".

A articulação do Porto Digital com o Estado se qualifica por intermédio desses acordos normatizados que ordenam a titulação do NGPD, considerando que essa lei regula tal interação:

Art. $2^{\circ}$ - 0 estado de Pernambuco, observado o contido na legislação aplicável, poderá celebrar contrato de gestão com a Associação Núcleo de Gestão do Porto Digital, com a interveniência das Secretarias de Planejamento e Gestão e da Fazenda, disciplinando as condições e os recursos financeiros a serem disponibilizados pelo Estado de Pernambuco para o desempenho das atividades públicas não-exclusivas a seu cargo, repassadas àquela entidade. ("Decreto Estadual", 2014, p. 7) 
0 artigo $2^{\circ}$ ilustra o desdobramento da articulação entre o Governo de Pernambuco e a OS NGPD, que passa a ser mediado legal e institucionalmente por micropráticas de poder (Foucault, 2014) presentes nas secretarias estaduais, as quais estruturam e reproduzem as normas institucionalizadas (Brígido, 2013) e reafirmam compromissos funcionais por meio de contratos de gestão, sob a vigilância normativa da Agência de Regulação dos Serviços Públicos Delegados de Pernambuco e da Controladoria Geral do Estado de Pernambuco. 0 relato abaixo é elucidativo a esse respeito:

O instrumento que amarra a relação da OS com o Estado é o contrato de gestão. O contrato de gestão é um contrato que se assemelha muito aos contratos privados aonde a OS, que é uma entidade privada, mediante a um programa de trabalho muito detalhado, se compromete a entregar metas para o Governo e, em contrapartida, o Governo transfere recursos para a sustentação dessas OS e a alimentação da sua capacidade de entregar essas metas. Então, a base do modelo de gestão do Porto Digital é o modelo de gestão de uma OS genérica. $(\mathrm{E} 6,2014)$

Por outro lado, os idealizadores do Porto Digital fizeram o esforço de tornar o parque uma OS e, principalmente, anunciá-lo como uma OS num esforço intencional de evitar possíveis interferências político-partidárias, como corrobora esse entrevistado: "nós temos uma governança profissional, independente do dia a dia da política, das trocas do cargo, do toma lá dá cá eleitoral, essas coisas que caracterizam parte da administração pública; as OS, de um modo geral, ficam à margem" (E6, 2014). Esse zelo se alinha à perspectiva de órgãos como o lasp, que têm um discurso essencialmente legalista e administrativo (Figlioli \& Porto, 2012). No entanto, para autores como Hall (2018), esse tipo de diligência revela as disputas e tensões dos atores sociais em meio às lógicas de dominação entre práticas e estruturas. Desse modo, essa amarração institucional descrita permitiu criar as normas de atuação do APL Porto Digital fora das contingências da administração pública vigente naquele contexto e expressa os interesses das lideranças que comandavam o processo na época.

A racionalidade ou o saber-poder vigente por trás da constituição do discurso pelo lado da elite tecnocrática do APL Porto Digital tinha como um dos seus fundamentos a constituição de uma hélice tríplice (triple helix) (Etzkowitz \& Zhou, 2017; Gomes \& Pereira, 2015), em que idealmente os agentes universidade, governo e empresas interagem numa estrutura normativa simétrica na produção de conceitos e conhecimentos relacionados aos problemas do setor empresarial. Dessa maneira, as tomadas de decisão, os objetivos estabelecidos e as rotinas construídas ocorrem no sentido de se construir um sistema territorial de inovação equilibrado e gerido como uma OS, materializada no NGPD.

Motivado também por um desejo de compreender o processo de estruturação e institucionalização em diferentes comunidades de prática que lidavam com gestão de projetos, Bresnen (2015) observou a existência de tensões e oportunidades que essa institucionalização traz e, adicionalmente, o ensejo por um viés profissionalizante de um corpo de conhecimento de modo a criar, nos termos de Thompson (1997), Kaur e Mazzarella (2009), Fonseca (2010) e Foucault (2014), a regulação das práticas institucionais vinculadas às relações dos agentes de mercado em detrimento das doutrinações de valores exercidas pelo poder público.

Constituem ainda a camada burocrática e executiva do Porto Digital as regulamentações emanadas das normas constitutivas do arranjo que estabelecem as atividades administrativas e institucionais e versam sobre as regras e normas que pavimentam o poder da tecnocracia, subordinando a organização, administração e decisão do NGPD a essas normativas (Brígido, 2013) e condenando as práticas que não se alinham a essa visão como desviantes, irracionais e antiprodutivas, tal como previsto no Estatuto Social (Porto Digital, 2018) e Regimento Interno do NGPD (Porto Digital, 2014).

$\mathrm{O}$ arcabouço legal que se apresenta de forma neutra, instrumental e excludente permite ao Porto Digital ter acesso aos recursos necessários a sua sustentabilidade econômica com legitimidade suficiente para que sua liderança não entre em conflito de interesses com outros atores relevantes da agenda políticoinstitucional 
do setor público que também almejam esses recursos ou comprometa seus resultados. Isso corrobora as perspectivas conceituais de Meirelles (2010), na medida em que valida orientações prescritas no artigo $5^{\circ}$ da Lei $n^{\circ} 17.244 / 2006$, em que são estabelecidas novas regras para que as empresas atreladas ao polo de informática do Recife possam ter acesso a benefícios fiscais viabilizados no programa de incentivos voltado para o Porto Digital.

O programa de incentivo ao Porto Digital foi revisto em 2011 com base na Lei $n^{\circ}$ 17.762/2011, a qual estendeu os benefícios fiscais para atividades vinculadas ao setor de TIC em conjunto com práticas tecnológicas e artísticas que também contemplam a esfera da economia criativa atrelados ao movimento de expansão do PqT Porto Digital com a inserção do Portomídia. Dessa forma, tal programa de incentivo passou a beneficiar essas atividades:

Tem a lei que cria e reconhece o Porto Digital como sendo um arranjo produtivo nesse território [Recife Antigo]. Tem outra lei que expande o território para Santo Amaro [o quadrilátero], que é uma tentativa da gente de criar uma reserva territorial para poder se expandir. $(\mathrm{E} 6,2014)$

As estruturas formais e instituições regulatórias tratadas no arranjo proporcionam uma materialização das políticas para o parque a partir de dupla expansão: (1) ampliação no escopo de sua atuação, pois incorporam os setores do Porto Digital vinculados a economia criativa aos benefícios contemplados nas políticas públicas previstas na lei; e (2) anexa ao território de atuação do Porto o quadrilátero localizado no bairro de Santo Amaro, especialmente para o desenvolvimento dos empreendimentos vinculados à economia criativa, assim, o surgimento do Portomídia.

0 poder econômico

O poder econômico é concebido como um sistema de classes (Thompson, 1997). Nessa tipologia de regulação cultural, essa dimensão de poder é exercida em meio a uma pluralidade de núcleos e pontos de apoio invisíveis e desconhecidos (Kaur \& Mazzarella, 2009). No Porto Digital, tal pluralidade é real, pois, mesmo antes da sua fundação, já existiam movimentos na cidade do Recife que almejavam a implementação de projetos que culminassem na diversificação da economia local e no desenvolvimento econômico-social do estado de Pernambuco (Corrêa, 2007). Essa retomada de crescimento da região seria amparada por novas oportunidades demarcadas pela emergência de plataformas de conhecimento, sistemas locais de inovação e geração de produtos e serviços com alto valor agregado (Cictec, 2013; Lacerda \& Fernandes, 2015; Porto Digital, 2013). Por outro lado, esse movimento pode levantar possíveis ameaças para os atores locais, tanto públicos quanto privados, a exemplo do deslocamento de atividades produtivas, fechamento de firmas e drenagem de cérebros dos setores tradicionais para os emergentes. Não obstante, esses efeitos múltiplos e opostos para o desenvolvimento local e regional em constante disputa são o reflexo, nos termos de Parrilli et al. (2016), de uma nova configuração de redes organizacionais de tecnologia que se projetam entre instâncias locais e globais de forma interconectada, em meio a uma dinâmica intensa na relação espaço-tempo dos polos geopolíticos de desenvolvimento. Isso fica evidente no relato a seguir:

Então, de um lado todo mundo já sabia, não era experiência só daqui, era no mundo, de você adensar empresas e criar polos tecnológicos, isso é uma coisa que funciona. Funciona no Vale do Silício [Califórnia/EUA], funciona em vários países do mundo, então, já tinha essa consciência e se estava procurando onde é que ela iria acontecer. Tinha uma hipótese de acontecer aqui na Várzea, porque é a terra da Universidade. Ao mesmo tempo, tinha outro problema; é que Cláudio [Marinho] sempre teve uma cabeça de urbanista. Cláudio, na época, era Secretário de Ciência e Tecnologia do Governo Jarbas. E ele entendia que o Recife antigo precisava ser recuperado como um espaço de uso da cidade, ele tinha feito já algumas 
melhorias lá, com os bares e umas coisas na época que ele estava na Prefeitura [do Recife], e aí, ao invés de criar um lugar distante de tudo, resolveram ocupar o Recife Antigo. (E1, 2014)

Nesses termos, os APL constituem referência para os novos atores coletivos das políticas de desenvolvimento com rubrica orçamentária pautada nos órgãos do governo e entidades fomentadoras, o que reforça os achados de autores como DattaGupta (2014) e Minguillo et al. (2015). É nesse contexto conflituoso que emergem as discussões sobre as parcerias público-privadas e as ideias sobre a participação dos diversos setores sociais nos negócios públicos, que dão espaço a um novo lócus investigativo emergente em torno das disputas pelos programas participativos, alteração dos arranjos políticos e modernização tecnológica (Mangematin et al., 2014). No nosso caso, o processo regulatório de tal participação deu origem às organizações da sociedade civil de interesse público e às OS, criadas em 1999, para tratar da transferência de responsabilidade do Estado para a sociedade civil nas áreas de serviços sociais, culturais, de pesquisa científica e tecnológica e de proteção ambiental, as quais representam a ressignificação das organizações não governamentais.

Oliveira (2003) considera que os principais objetivos dessas organizações tuteladas pelo Estado se pautam por normatizar a relação desses atores com a sociedade e estimular o crescimento do terceiro setor claro que dentro da concepção hegemônica do desenvolvimento econômico. Ao ilustrar essa demarcação regulatória, o APL Porto Digital se apresenta como o expoente de uma nova elite econômica emergente em Pernambuco, capaz de impulsionar o desenvolvimento local, diferentemente da liderança socioeconômica tradicional, a sucroalcooleira (Corrêa, 2007; Lacerda \& Fernandes, 2015). Nesse contexto histórico, o engenho era uma organização social que se desdobrava em organização de prestígio e influência política.

O Porto Digital desafiou os setores tradicionais ao trazer um conhecimento valorizado, detentor dos elementos discursivos legitimadores da onda liberal e da globalização capitalista vigente. Esse posicionamento se materializa na tecnologia aplicada aos processos de negócios novos e existentes, ao mesmo tempo que é travada a batalha de desvalorização econômica, cultural e estética com respeito às formas sociais anteriores. Além disso, o crescimento da classe econômica vinculada ao Porto Digital tende a ser avaliado a partir da experiência global de elevadas taxas de crescimento econômico, que ocorreram na chamada Terceira Itália e no Vale do Silício, gerando certo número de empregos bem remunerados e se posicionando entre as rendas per capita mais elevadas do primeiro mundo (Lacerda \& Fernandes, 2015), e segundo relatórios da Cictec (2013) quando se constata que o Porto Digital tem sido exitoso em reunir os elementos necessários para seu funcionamento satisfatório e sua efetiva articulação com o tecido produtivo local (Boschma \& Frenken, 2012). Esse esforço tem sido complementado com certa vigilância estratégica, no sentido de que seja expandido seu escopo de atuação para a esfera da economia criativa. Tal cenário tem servido de esteio para o Porto Digital ocupar a posição hegemônica de locomotiva do desenvolvimento econômico do estado de Pernambuco e se colocar como uma nova classe econômica capaz de impulsionar o desenvolvimento local.

O PD [Porto Digital] foi criado para ser uma espécie de plataforma da nova economia da cidade do Recife. Na época se chamava a nova economia, economia do conhecimento, economia intensiva em tecnologia da informação (TI).... O PD era, portanto, a ideia de termos aqui um sistema local de inovação capaz de [re]articular esse potencial que a gente tinha perdido ou vinha perdendo na área de TI e criar um polo de desenvolvimento de software de classe mundial. (E6, 2014)

Esse lugar the trouxe condições favoráveis em suas disputas por recursos materiais e simbólicos no campo político e econômico. Foi construído um discurso que apresenta a potencialidade de oferecer rápidos resultados diante dos investimentos em infraestrutura relativamente menores do que os exigidos por outros setores de tecnologia, como já é comprovado no Relatório de economia criativa 2010 ("Relatório de", 2012), no estudo da Anprotec (2014) e nos estudos de autores como DattaGupta (2014) e Liefooghe (2015). Uma empresa de software pode atuar sem instalações sofisticadas, laboratórios ou maquinários requeridos em 
outras atividades, a exemplo do setor de microeletrônica orientada para a produção de hardwares. Nesse aspecto, a opção do desenvolvimento local - via TIC - pode ser significada não apenas como um caminho natural, mas como uma ação política em detrimento de outras classes produtivas. Os pontos que apoiam estes discursos antagônicos representam considerações significativas no sentido de que a opção pelo setor de software ocorreu em detrimento de/ou subordinando projetos iniciados em governos anteriores, por adversários partidários como, por exemplo, o PqT de Eletroeletrônica (Parqtel), que 20 anos depois não conseguiu ocupar um lugar de protagonismo semelhante ao Porto Digital.

O Porto Digital foi convidado e era o Porto Digital que estava tocando a gestão do ParqTel. Que é de eletrônica, num é? Que também é área-meio, entendeu? Então, mas a estratégia aí... era outra circunstância, porque o ParqTel não estava deslanchando, e aí, o Governo do Estado achou que a expertise que o Porto Digital tinha adquirido em gerir parques tecnológicos poderia ser transferida na gestão do ParqTel. (E1, 2014)

O processo de transferência de conhecimento do Porto Digital para o Parqtel ganha fôlego com a participação das classes privadas na governança do Porto, fato que se materializa pela representação das entidades privadas de TIC, a saber: o Centro de Excelência em Tecnologia de Software do Recife (Softex), a Associação das Empresas Brasileiras de Software e Serviços de Informática (Assespro) e o C.E.S.A.R. Essas agremiações fazem parte do grupo que batalha pela construção do tom modernizador do Porto Digital e estão imbricadas numa complexa dinâmica de parcerias, como atestam os estudos de VásquezUrriago et al. (2016). A importância desses dois entes relacionados aos setores da TIC para o Porto Digital é reforçada por um dos entrevistados, E3, para quem o órgão tem uma instância intermediária denominada de comitê tático, "que envolve Porto Digital, Assespro e Softex, aqueles componentes mais táticos do dia a dia em que a implementação de certo projeto estratégico para o setor tenha alguma dificuldade. A gente se reúne e trabalha junto" (E3, 2014)".

A expansão territorial e do escopo de atuação do Porto Digital representa um sinal de força política e econômica de sua classe dirigente, o que ilustra o fato de ser fruto da associação de alguns atores-chave articulando essa expansão. Igualmente, apesar de tanto os formuladores da legislação da cidade do Recife quanto os responsáveis pelo Estatuto Social do arranjo vislumbrarem a sua expansão por meio da criação do Portomídia, na prática, a estrutura do Conselho de Administração do Porto Digital, assim como dos demais órgãos relacionados ao APL, permaneceu intacta, ou seja, agindo sem a presença efetiva de representações por parte das empresas de economia criativa, ao contrário das empresas de TIC, que possuem assento e ainda se fazem representar por meio da Assespro e Softex.

O PD nunca vai virar as costas para TIC. Um indício claro, é que o conselho e a composição do conselho não mudaram. E ela [a composição do conselho de gestão do Porto Digital], tem a ASSESPRO, tem a SOFTEX, as empresas, pois, poderia ter empresas de economia criativa, mas, só tem empresas de TIC. Todo o DNA do Porto Digital é TIC. (E1, 2014)

Para a construção desse posicionamento, foram utilizadas justificativas que visavam ressaltar a importância central que a indústria de software possui para a inserção do estado de Pernambuco no mercado global emergente de tecnologias. A argumentação se apoia na ideia de que existe um setor transversal, que produz as ferramentas a serem utilizadas por praticamente todos os outros setores, a fim de que se tornem competitivos na economia global. Desse modo, a indústria de software se apresenta como aliada a outros setores, e não como competidora por espaço da política econômica local e nacional. Esse posicionamento representa um deslocamento para um éthos articulador das diferenças de diversos elementos no campo de disputa de sentidos nessa cadeia produtiva. 
À semelhança dos processos articulatórios descritos por Sergeeva (2016) no Reino Unido, essa categoria se relaciona aos elementos observados no caso investigado, uma vez que esse processo é dirigido pelo poder econômico de uma classe que, na sua composição, tem uma governança articulada pela intervenção direta do Estado por meio de empresas públicas e órgãos reguladores independentes, que vão moldando e sendo moldados por forças inseridas no mercado das empresas de TIC, que, por sua vez, articulam o setor de economia criativa no contexto pernambucano.

0 poder subjetivo

O poder subjetivo representa certa autonomia, senso de realização pessoal e forma de verificação do relacionamento entre a realidade e destino das lideranças, potencializando a responsabilidade individual, além de gerar projetos pessoais e configurar dimensões decisórias na esfera subjetiva de seu cotidiano (Ayeni, 2018; Rose, 2011; Silkenbeumer et al., 2016; Thompson, 2015).

0 poder subjetivo constitui um tipo de regime equivalente àquele estabelecido pelos poderes institucional e econômico, em decorrência do efeito específico de mobilização dos atores a partir de pontos de convergência momentânea. Em se tratando da atuação desses protagonistas no território do Porto Digital, ocorre a busca por sinergia e complementaridade entre tais decisores, cujas características são identificadas no discurso que compõe o APL:

\begin{abstract}
Foi eu que coordenei, para a criação do Delta Zero. Na época, a gente fez todo um estudo, envolvendo mais de 200 pessoas, envolvemos na discussão sobre economia criativa em Recife. Então, foram convergências que estavam rolando em paralelo. Do jeito, aliás, é preciso dizer que o projeto Finep [Financiadora de Estudos e Projetos], ele já era para criar um polo de cine-animação aqui. E veio ampliando para um polo de economia criativa, que na época a gente não tinha nem esse nome... foi só no fim que apareceu. A gente chamava de produção de conteúdo cultural... nem nome tinha... entendeu? Então, em paralelo, aí, a ordem histórica, eu comecei... o Porto Digital começou, mas independentemente da gente, depois fui convergindo... o governo do estado, dentro da Secretaria de Desenvolvimento Econômico, eu tenho até uma figura disso, foi com o programa PE Criativo, também, achando que isso era importante, e a Prefeitura lançou esse estudo também; então, houve convergências de que era importante olhar para a economia criativa de vários atores diferentes. $(\mathrm{E} 1,2014)$
\end{abstract}

Nota-se a construção de um discurso beatificado que protagoniza a ação individual em meio às relações de força e os feitos do poder econômico e institucional, ou seja, os jogos de interesse que permeiam as interações humanas e institucionais, sendo eleitas formas (modelos) de governança que permitem a adesão de outros atores. Com isso, identificamos a concepção de Thompson (1997, 2015), Rose (2011), Hall (2016) e Ayeni (2018) quando apontam novos caminhos com respeito à relação entre poder e visibilidade, chamando atenção para o modo como a subjetividade se torna recurso essencial para os procedimentos de regulação.

Quanto ao processo de expansão, a atividade de TIC é considerada área-meio, ou seja, ela cria instrumentos para o desenvolvimento de outras áreas no que concerne à operacionalização de suas funções primordiais, como é o que acontece no ramo da economia criativa, em que os softwares dão suporte em suas plataformas tecnológicas para a melhoria de artefatos oriundos de áreas como música, games ou livros digitais. Com base em estudos realizados pelo CGEE (2011) e pela Oremi Consultoria e Mega Consultores (2010), observou-se que essas lideranças decidiram pela expansão do arranjo, tratando de alterar o seu Estatuto Social e influenciar na atualização das leis vigentes no Recife, de modo a incorporar alguns setores criativos nos benefícios já proporcionados às empresas de TIC e materializados na estratégia de construção do Portomídia, conforme assinala o relato a seguir: 
Isso já vinha sendo costurado antes, porque a prefeitura tem assento no conselho do Porto Digital. Agora, em paralelo, teve uma discussão, ainda com João da Costa [ex-prefeito do Recife], sobre as vocações da cidade do Recife, e foi feito um estudo com Cláudio Marinho [CGEE, 2011] que bebeu do documento de planejamento estratégico financiado por mim, por meio da Finep, para a criação do Delta Zero. Na época, a gente fez todo um estudo, envolvendo mais de 200 pessoas, envolvemos na discussão sobre economia criativa no Recife. (E1, 2014)

Esse trecho ilustra um aspecto significativo da atuação do poder subjetivo na regulação de um PqT, ao mostrar como as forças das lideranças individuais, nos termos de Parrilli et al. (2016), direcionam o polo, influenciando nos caminhos a serem trilhados, pois a expansão do Porto Digital está associada ao processo de escolhas dos setores criativos que mais dialogariam com as atividades de TIC presentes nesse arranjo. Nesse sentido, as escolhas foram realizadas da seguinte maneira:

Os que tinham uma dependência maior da tecnologia. Esse é o recorte que Chico Saboya tomou, ele tem um discurso um pouco diferente para o público. Ele vai dizer que tem umas áreas que são assim, que ele considera que é, e outras que ele considera que não é economia criativa, mas tudo conversa fiada, entendeu? O básico, e seria muito mais fácil de dizer, em vez de criar polêmicas, é dizer "o PD recorta!" E eu fiz o trabalho com ele: quais os setores, nos próximos anos, que terão um maior impacto da tecnologia e do design? Fez um gráfico todinho, e os setores que possuem mais impacto foi esse que ele disse: são esses que eu vou tomar conta. (E1, 2014)

Essa atuação empreendedora revela um tipo de arranjo organizacional em que há unidades individuais competindo entre si no interior do polo, criando as regras institucionais para a conduta e existência diária sob a égide do que Rose (2011) enumera como iniciativa, ambição, cálculo e responsabilidade pessoal. Tais formas de atuação representam um self empreendedor que formula estratégias de maximização do próprio capital humano, projetando um cenário favorável de ajuste a seus interesses. Logo, a liderança do grupo consegue fazer escolhas sobre as práticas e institucionalidades por meio da sua autoridade, conhecimento, coerção e legitimidade, que acabam por reforçar sua dominação sobre o setor de TIC e alçar maior protagonismo entre os demais setores.

O perfil do gestor influencia na sua relação com as associações que lideram o setor nas lutas por suas demandas. Essas entidades são espaços de atuação política nos quais essas lideranças costuram consensos diante das posições plurais e frequentemente antagônicas que envolvem universidades, governo e associações empresariais. Desse modo, estudos como o de Correia e Gomes (2012) carecem de um aprofundamento teórico e empírico, uma vez que, ao analisarem a relevância dos PqTs como habitats de inovação no desenvolvimento da Região Nordeste, trazem uma abordagem teórica e metodológica limitada para entender os esforços de difusão de uma nova cultura empreendedora na região, concebida como um fenômeno multifacetado e dinâmico em que os atores-chave atuam no interior de estruturas sociais intricadas, nos termos descritos por Thompson (1997) e Foucault (2014).

O C.E.S.A.R. exerce liderança inconteste sobre os rumos do Porto Digital, em função da influência exercida pela regência de seu diretor-geral de dimensão icônica, Silvio Meira, e seu capital social. 0 protagonismo e autodisciplina desse dirigente tem Ihe permitido delinear os caminhos do Porto Digital e identificar oportunidades de negócio nos setores atrelados à atividade de TIC. Portanto, as interlocuções desse intelectual orgânico, em conjunto com personagens decisivos do meio acadêmico, do mercado e de instâncias governamentais, ilustram a sua capacidade de articulação sociopolítica, nos termos descritos por Hall (2018).

A busca pela cooperação entre as principais lideranças de um PqT nem sempre ocorre de maneira harmoniosa e simples, como fazem crer estudos como os de Vásquez-Urriago et al. (2016), quando 
analisam os benefícios da inserção de firmas no âmbito de polos tecnológicos domiciliados na Espanha. Nesses espaços, relações conflituosas podem ocorrer por tensões e disputas entre a dependência e a diversidade de objetivos dos atores imersos em relações de rede de intercâmbio tecnológico e comercial (Rodríguez-Pose, 2014; Thompson, 1997).

As práticas articulatórias que resultaram na criação do Porto Digital e, por decorrência, do arranjo institucional Portomídia o tornam um sujeito complexo constituído por atores heterogêneos, contendo particularidades que podem desestabilizá-lo. No entanto, a compreensão do poder subjetivo na regulação cultural do processo de expansão para incluir o Portomídia permite entender as dimensões políticas e culturais que estão subjacentes aos discursos dos atores que conseguem costurar de forma contingencial as diferentes demandas. Essa pregação ficou evidente na forma como os atores constituintes do Portomídia posicionaram esse equipamento como ferramenta de desenvolvimento econômico de setores de economia criativa.

\section{Considerações finais}

A problemática teórica desenvolvida ao longo do estudo teve como intuito ultrapassar os limites explicativos dos conceitos desenvolvidos sob a égide do poder econômico para se pensar a regulação de modo a incorporar a força explicativa dos conceitos de poder institucional e subjetivo, que permitiram compreender a concepção de um PqT como um espaço dinâmico de articulações e disputas vivenciadas por diferentes protagonismos em meio às cadeias produtivas atreladas ao referido arranjo. Esse esforço foi efetivado no sentido de se compreender o processo de regulação cultural como forma de ampliação de um PqT de TIC num polo de economia criativa. Assim, propusemos como objetivo central do estudo desvelar o modo como ocorreu o processo regulatório de expansão do escopo de atuação do Porto Digital, culminando na criação do arranjo institucional Portomídia.

A expansão de um PqT ocorre pela intensificação das dinâmicas articulatórias movidas pelos líderes das redes e suas parcerias. A esse esforço é somado o estreitamento da relação entre as organizações e os atores envolvidos na construção dos seus respectivos artefatos cooperativos na esfera tecnológica. As particularidades dessa articulação fazem com que o entendimento do processo regulatório pela ótica econômica não consiga dar conta do universo simbólico desses arranjos.

Do ponto do poder institucional, o caso ilustrativo do APL Porto Digital é característico de um conglomerado tecnológico que emerge de um conjunto de leis que o institui como uma OS governada por uma hélice tríplice (triple helix), nos termos de Etzkowitz \& Zhou (2017), representada por um conselho de governança, como o NGPD e o seu Conselho de Administração. Além disso, as regras e regulamentações estabelecidas revelam sua atribuição no sentido de serem criados os benefícios derivados de marcos regulatórios, a exemplo da redução dos impostos, e os formatos de funcionamento de determinado arranjo institucional, como o Estatuto e Regimento Interno.

Em se tratando do poder econômico sobre o qual o poder político dos atores envolvidos é exercido, verificamos que, apesar da expansão, um arranjo como o Porto Digital e a estrutura por ele criada para embarcar os setores de economia criativa entrantes não sofrem grandes modificações, uma vez que são entidades governadas sob a lógica majoritária dos setores/classes tradicionais de TIC. Nesse caso, o Porto Digital criou um comitê tático, representado pelo NGPD, a Assespro e Softex, que articulam os projetos estratégicos do Porto. Essa composição política ilustra o modo como o poder é exercido por atores que detêm maior domínio de recursos, uma vez que, apesar da existência de um discurso integrador, pesa a influência daqueles portadores de funções significativas no nível estratégico e tomadores-chave de decisão que viabilizam a governança do parque.

Com respeito ao poder subjetivo, em que estão situados os discursos e as práticas dos interagentes diante das estruturas institucionais e econômicas, as principais lideranças atuam no processo imediato de 
expansão para a criação de polos criativos de base informacional. Logo, existe um esforço de lideranças vinculadas diretamente ao conselho diretivo para a produção de uma convergência, ampla a ponto de ser capaz de representar as outras demandas dos atores da economia criativa e de outros setores relevantes do estado, no que tange a financiamento e flexibilização nas estruturas legais que privilegiem as TIC, além de contemplarem as áreas de transferências tecnológicas.

Um achado do estudo reside na constatação da existência de um self empreendedor tanto ativo como articulador, que atua além dos limites dos designs institucionais vigentes, moldando-os de modo a produzir resultados mais de acordo com os seus interesses. Logo, a dinâmica de expansão territorial de um polo criativo confere certa autorregulação aos atores-chave, conduzida por uma racionalidade pragmática que busca orquestrar projetos estruturadores em conjunto com outras lideranças dirigidas para 0 alcance de objetivos compartilháveis.

A autorregulação de um PqT não se estabelece apenas por um marco legal, pois este é consequência de práticas que estão ao seu entorno. Além disso, não podemos esquecer que hoje as organizações são avaliadas pelas suas capacidades de promover ações empreendedoras de parte das lideranças, estimulando-as a se comportar com autonomia, criatividade e a aceitar riscos na busca para alcançar a eficiência coletiva. Essas são as práticas de regulação contemporânea par excellence.

0 estudo sugere a demarcação de novas inquietações no que diz respeito ao aprofundamento e a indicações para futuras pesquisas que aclarem os temas relativos à regulação de arranjos produtivos. A incorporação das abordagens, como os EC, intentou revelar a limitação da visão reducionista, mecanicista, econômica (vinda do positivismo e que ainda domina a formulação de políticas e resolução de problemas), e revelar a complexidade e a contradição como elemento inerente e irredutível da realidade. Assim, é necessário se aprofundar nas abordagens que se propõem a navegar esse cenário a partir de metodologias apropriadas que permitam aos pesquisadores culturais estabelecer modelos teoricamente informados e empiricamente fundamentados. Além disso, é necessário que os estudos organizacionais considerem que, em contextos globais marcados pela pluralidade, surge o desafio de reconhecimento da diferença e da capacidade de se construir posições negociadas, de modo a intercambiar institucionalmente o movimento de ampliação de estruturas organizacionais complexas, como as relacionadas às indústrias criativas, que demandam destreza operacional, pensamento lateral, capacidade de improvisação e práticas regulatórias que estão além do nosso controle e previsão. Aqui podemos indagar, para futuros estudos, de que modo e com que consequências nossas concepções sobre poder subjetivo e self empreendedor estão incorporadas nas ações de regulação de territórios criativos que florescem do capitalismo cognitivo? Certamente, aqui já estamos falando de uma segunda geração de políticas de suporte para PqTs e, desse modo, de novos estudos teóricos e empíricos que delineiem metodologias que deem conta do desenvolvimento econômico, institucional e das lideranças empreendedoras engajadas com o desenvolvimento local.

\section{Referências}

Almeida, S. L. (2012). Inovação e [re]articulação de significados culturais: Disputas e alianças pela atribuição de sentidos ao queijo de coalho artesanal no contexto da indicação geográfica "Agreste de Pernambuco" (Tese de doutorado). Universidade Federal de Pernambuco, Recife, PE.

Associação Nacional de Entidades Promotoras de Empreendimentos Inovadores. (2014). Estudo de projetos de alta complexidade: Indicadores de parques tecnológicos. Brasília, DF: Centro de Apoio ao Desenvolvimento Tecnológico/UnB.

Ayeni, O. (2018). The dynamics of circuit of culture model in promoting Angelina Jolie's humanitarian activities. Studies in Media and Communication, 6(2), 12-19. doi:10.11114/smc.v6i2.3493 
Bauer, M. W., \& Gaskell, G. (2002). Para uma prestação de contas pública: além da amostra, da fidedignidade e da validade. In Pesquisa qualitativa com texto, imagem e som: Um manual prático (pp. 470-490). Petrópolis, RJ: Vozes.

Bauman, Z. (1999). Globalização: As consequências humanas. Rio de Janeiro, RJ: Zahar.

Boschma, R., \& Frenken, K. (2012). Technological relatedness and regional branching. In H. Bathelt, M. Feldman, \& D. F. Kogler (Eds.), Beyond territory: Dynamic geographies of knowledge creation, diffusion and innovation (pp. 64-81). London: Routledge.

Bresnen, M. (2015). Institutional development, divergence and change in the discipline of project management. International Journal of Project Management, 34(2), 328-338. doi:10.1016/j.ijproman.2015.03.001

Brígido, E. (2013). Foucault: Michel Foucault: Uma análise do poder. Revista de Direito Econômico e Socioambiental, 4(1), 56-75. doi:10.7213/rev.dir.econ.socioambienta.04.001.A003

Butler, J. (2014). Regulações degênero. Cadernos Pagu, (42), 249-274. doi:10.1590/0104-8333201400420249

Centro de Gestão e Estudos Estratégicos. (2011). Inovações tecnológicas e cadeias produtivas selecionadas: Oportunidades de negócios para o município de Recife (PE) (Série Documentos Técnicos, n. 10). Brasília, DF: Autor.

Chomsky, N., \& Foucault, M. (1971). Human nature: Justice versus power. Recuperado de http://bit.ly/37KIZAX

Cictec. (2013). Porto Digital: Criatividade, inovação e empreendedorismo. Trabalho apresentado no $3^{\circ}$ Seminário Cictec: Inovação e Competitividade na Economia Criativa, Recife, PE. Recuperado de http://bit.ly/334sUVI

Corrêa, M. I. S. (2007). Os novos tempos e a constituição discursiva do sujeito coletivo: Um estudo no campo do empreendedorismo no setor de tecnologia da informação e comunicação (Dissertação de Mestrado). Universidade Federal de Pernambuco, Recife.

Correia, A. M. M., \& Gomes, M. L. B. (2012). Habitat's de inovação na economia do conhecimento: Identificando ações de sucesso. Revista de Administração e Inovação, 9(2), 32-54. doi:10.5773/ rai.v9i2.673

Creswell, J. W. (2010). Projeto de pesquisa: Métodos qualitativo, quantitativo e misto (3a ed.). Porto Alegre, RS: Artmed.

DattaGupta, O. (2014). Global integration and developing Indian "smart cities": New hopes and challenges. International Journal of Innovative Social Science \& Humanities Research, 1(2), 30-42. Recuperado de http://bit.ly/38KkWTL

Decreto $n^{\circ}$ 23.046, de 19 de fevereiro de 2001. (2001). Regulamenta a Lei $n^{\circ} 11.743$, de 20 de janeiro de $2000, \ldots$ Recife, PE. Recuperado de http://bit.ly/3bRkkOl

Decreto $n^{\circ}$ 40.568, de $1^{\circ}$ de abril de 2014. (2014). Renova a titulação da Organização Social que indica. Recife, PE. Recuperado de http://bit.ly/32hrxCL

Denzin, N. K. (2009). The research act: A theoretical introduction to sociological methods. New Brunswick: Transaction.

Denzin, N. K., \& Lincoln, Y. S. (2006). O planejamento da pesquisa qualitativa: Teorias e abordagens (2a ed.). Porto Alegre, RS: Artmed.

Du Gay, P., Hall, S., Janes, L., Mackay, H., \& Negus, K. (2013). Doing cultural studies: The story of the Sony walkman. London: Sage. 
Escosteguy, A. C. D. (2013). Cartografias dos estudos culturais: Uma versão latino-americana. Porto Alegre, RS: Autêntica.

Escosteguy, A. C. D. (2018). Estudos culturais latino-americanos e Jesús Martín-Barbero: Mais afinidades do que disputas. MATRIZes, 12(1), 99-113. doi:10.11606/issn.1982-8160.v12i1p99-113

Etzkowitz, H., \& Zhou, C. (2017). Hélice Tríplice: Inovação e empreendedorismo universidade-indústria-governo. Estudos Avançados, 31(90), 23-48. doi:10.1590/s0103-40142017.3190003

Figlioli, A., \& Porto, G. S. (2012). Financiamento de parques tecnológicos: Um estudo comparativo de casos brasileiros, portugueses e espanhóis. Revista de Administração, 47(2), 290-306. doi:10.1590/S008021072012000200010

Fonseca, M. A. (2010, 31 de março). A época da norma. Revista Cult, 134(3).

Foucault, M. (2014). Microfísica do poder (28a ed.). São Paulo, SP: Paz \& Terra.

Foucault, M. (2016). The subject and power. In H. Dreyfus, \& P. Rabinow (Orgs.), Michel Foucault: Beyond structuralism and hermeneutics (pp. 225-254). Abingdon: Routledge.

Gargione, L. A. (2011). Um modelo para financiamento de parques tecnológicos no Brasil: Explorando o potencial dos fundos de investimento (Tese de doutorado). Universidade de São Paulo, São Paulo, SP.

Gomes, M. A. S., \& Pereira, F. E. C. (2015). Hélice Tríplice: Um ensaio teórico sobre a relação UniversidadeEmpresa-Governo em busca da inovação. International Journal of Knowledge Engineering and Management, 4(8), 136-155. Recuperado de http://bit.ly/38MKwHZ

Hall, S. (2016). O Ocidente e o resto: Discurso e poder. Projeto História, 56, 314-361. Recuperado de http://bit.ly/38Xi6e8

Hall, S. (2018). Da diáspora: Identidades e mediações culturais (2a ed.). Belo Horizonte, MG: Editora UFMG.

Hallam, E., \& Ingold, T. (2008). Creativity and cultural improvisation. London: Berg Publishers.

Hardt, M., \& Negri, A. (2006). Império (8a ed.). Rio de Janeiro, RJ: Record.

Ho, S. C. F. (2016). Between the museum and the public: Negotiating the "circuit of culture" as an analytical tool for researching museums in China. International Journal of the Inclusive Museum, 9(4), 17-31. doi:10.18848/1835-2014/CGP/v09i04/17-31

Ipiranga, A. S. R., Faria, M. V. C. M., \& Amorim, M. A. (2008). A comunidade de prática da rede nós: Colaborando e compartilhando conhecimentos em arranjos produtivos locais. Organizações \& Sociedade, 15(44), 149-170. doi:10.1590/S1984-92302008000100008

Johnson, R. (2007). O que é, afinal, estudos culturais? In T. T. Silva (Org.), O que é, afinal, estudos culturais? (2a ed., pp. 7-132). Belo Horizonte, MG: Autêntica.

Kaur, R., \& Mazzarella, W. (Eds.). (2009). Censorship in South Asia: Cultural regulation from sedition to seduction. Bloomington: Indiana University Press.

Lacerda, N., \& Fernandes, A. C. (2015). Parques tecnológicos: Entre inovação e renda imobiliária no contexto da cidade do Recife. Cadernos Metrópole, 17(34), 329-354. doi:10.1590/2236-9996.2015-3402

Lei Estadual no 11.743, de 20 de janeiro de 2000. (2000). Sistematiza a prestação de serviços públicos não exclusivos... Recife, PE. Recuperado de http://bit.ly/2wzCsMu

Lei Municipal $n^{\circ}$ 17.244, de 27 de julho de 2006. (2006). Institui o programa de incentivo ao Porto Digital mediante a concessão de benefícios fiscais condicionados. Recife, PE. Recuperado de http://bit.ly/2PcXgQf 
Lei Municipal $n^{\circ}$ 17.762, de 28 de dezembro de 2011. (2011). Introduz alterações nas leis municipais $n^{0} 17.244 / 2006$ e no 17.237/2006. Recife, PE. Recuperado de http://bit.ly/38Nfuj3

Liefooghe, C. (Dir.). (2015). L'économie créative et ses territoires: Enjeux et débats. Rennes: Presses Universitaires de Rennes.

Lincoln, Y. S., \& Guba, E. G. (1985). Naturalistic inquiry. Newbury Park: Sage Publications.

Link, A. N. (2009). Research, science, and technology parks: An overview of the academic literature. In Understanding research, science and technology parks: global best practices: report of a symposium for the National Research Council (pp. 127-139). Washington, D.C.: National Academy Press.

Malik, S., Chapain, C., \& Comunian, R. (2017). Rethinking cultural diversity in the UK film sector: Practices in community filmmaking. Organization, 24(3), 308-329. doi:10.1177/1350508416689094

Mangematin, V., Sapsed, S., \& Schüßler, E. (2014). Disassembly and reassembly: Introduction to the Special Issue on digital technology and creative industries. Technological Forecasting and Social Change, 83, 1-9. doi:10.1016/j.techfore.2014.01.002

Martins, G. A. (2008). Estudo de caso: Uma reflexão sobre a aplicabilidade em pesquisa no Brasil. Revista de Contabilidade e Organizações, 2(2), 8-18. doi:10.11606/rco.v2i2.34702

Mattelart, A., \& Neveu, É. (2004). Introdução aos estudos culturais. São Paulo, SP: Ed. Parábola.

Meirelles, D. S. (2010). Teorias de mercado e regulação: Por que os mercados e o governo falham? Cadernos EBAPE.BR, 8(4), 644-660. doi:10.1590/S1679-39512010000400006

Mello, S. C. B., \& Cordeiro, A. T. (2010). Investigando novas articulações e possibilidades no discurso empreendedor: Contexto, sujeito e ação. Organizações \& Sociedade, 17(53), 279-295. doi:10.1590/ S1984-92302010000200003

Minguillo, D., Tijssen, R., \& Thelwall, M. (2015). Do science parks promote research and technology? A scientometric analysis of the UK. Scientometrics, 102, 701-725. doi:10.1007/s11192-014-1435-z

Motta, F. C. P., \& Alcadipani, R. (2004). O pensamento de Michel Foucault na teoria das organizações. Revista de Administração, 39(2), 117-128. Recuperado de http://bit.ly/2T2zilL

Oliveira, F. M. (2003). Cidadania e cultura política no poder local: O Conselho da Administração Participativa de Camaragibe - PE (Dissertação de mestrado). Universidade Federal de Pernambuco, Recife, PE.

Oremi Consultoria, \& Mega Consultores. (2010). Modelagem conceitual e planejamento de cenários do polo de produção de conteúdo cultural de Pernambuco: Relatório Final. Recife: Autor.

Parrilli, M. D., Nadvi, K., \& Yeung, H. W.-C. (2016). Local and regional development in global value chains, production networks and innovation networks: A comparative review and the challenges for future research. In M. D. Parrilli (Ed.), The competitiveness of clusters in globalized markets: Implications for regional development (pp. 1-22). London: Routledge.

Payne, M. (2015). Modern social work theory (4a ed.). Don Mills: Oxford University Press.

Porto Digital. (2013). Parque. Recuperado de http://bit.ly/2wDX5XY

Porto Digital. (2014). Regimento interno do Núcleo de Gestão Porto Digital. Recuperado de http://bit.ly/2wC9tHR

Porto Digital. (2018). Décima reforma do estatuto social - consolidado. Recuperado de http://bit.ly/39xHXtD

Relatório de economia criativa 2010: Economia criativa uma, opção de desenvolvimento. (2012). Brasília, DF: Secretaria da Economia Criativa/Ministério da Cultura. 
Rodríguez-Pose, A., \& Hardy, D. (2014). Technology and industrial parks in emerging countries: Panacea or pipedream? London: Springer.

Rose, N. (2011). Inventando nossos selfs: Psicologia, poder e subjetividade (Col. Psicologia Social). Petropolis, RJ: Vozes.

Sergeeva, N. (2016). What makes an "innovation champion"?. European Journal of Innovation Management, 19(1), 72-89. doi:10.1108/EJIM-06-2014-0065

Silkenbeumer, J., Schiller, E.-M., Holodynski, M., \& Kärtner, J. (2016). The role of co-regulation for the development of social-emotional competence. Journal of Self-Regulation and Regulation, 2, 16-33. doi:10.11588/ josar.2016.2.34351

Silva, J. S. (2012). O capital social como ativo nas redes interorganizacionais: Um estudo sobre a inovação no setor de games de Pernambuco (Dissertação de mestrado). Universidade Federal de Pernambuco, Recife, PE.

Stake, R. E. (1999). The art of case study research (2a ed.). London: Sage.

Stake, R. E. (2005). Qualitative case studies. In N. K. Denzin, \& Y. S. Lincoln (Eds.), The Sage handbook of qualitative research (pp. 443-466). London: Sage.

Steiner, J. E., Cassim, M. B., \& Robazzi, A. C. (2008). Parques tecnológicos: Ambientes de inovação. Recuperado de http://bit.ly/2PcP3LM

Šupa, M. (2015). Mapping practices of social control: A Foucauldian analysis of urban space. Criminological Studies, (3), 82-123. doi:10.15388/CrimLithuan.2015.0.8951

Thompson, K. (1997). Regulation, de-regulation and regulation. In K. Thompson (Ed.), Media and cultural regulation (pp. 9-68). London: Sage.

Thompson, K. (2015). Moral regulation: Beyond Janet Jackson and the passion. In I. Reed, \& J. C. Alexander (Eds.), Meaning and method: The cultural approach to sociology (pp. 63-76). New York: Routledge.

Thorpe, R. (2008). Introduction: Constructionist approaches to management research. Management Learning, 39(2), 115-121. doi:10.1177/1350507607087966

Vásquez-Urriago, Á. R., Barge-Gil, A., \& Rico, A. M. (2016). Science and technology parks and cooperation for innovation: Empirical evidence from Spain. Research Policy, 45(1), 137-147. doi:10.1016/j. respol.2015.07.006

Weber, M. (2013). A ética protestante e o espírito do capitalismo. São Paulo, SP: Martin Claret.

Whelan, C. (2016). Organisational culture and cultural change: A network perspective. Australian \& New Zealand Journal of Criminology, 49(4), 583-599. doi:10.1177/0004865815604196

Williams, R. (1974). Television: Technology and cultural form. London: Fontana.

\section{Agradecimentos}

À Coordenação de Aperfeiçoamento de Pessoal de Nível Superior.

\section{Sobre os Autores}

\section{Anderson Diego Farias da Silva}

Mestre em administração pela Universidade Federal de Pernambuco. Professor pesquisador do Bacharelado em Administração Pública da Universidade Federal Rural de Pernambuco e do Centro Universitário Facol. Membro do Grupo de 
Pesquisa Lócus de Investigação em Economia Criativa. Especialista em administração de marketing pela Universidade de Pernambuco. Foi estudante de doutorado visitante na École des Hautes Études Commerciales de Montréal (Canadá). E-mail: andersondiego6@gmail.com. ORCID: 0000-0002-9793-6512

\section{Nelson da Cruz Monteiro Fernandes}

Doutor em administração pela Universidade Federal de Pernambuco (UFPE). Professor do Núcleo de Gestão da UFPE campus Avançado do Agreste -, do Programa de Pós-Graduação em Gestão, Inovação e Consumo e do Programa de Pós-Graduação em Propriedade Intelectual e Transferência de Tecnologia para a Inovação. Fez mestrado em sociologia na UFPE. Membro do Grupo de Pesquisa Lócus de Investigação em Economia Criativa. E-mail: cruzfernandes55@gmail.com. ORCID: 0000-0002-1662-9300

\section{Fernando Gomes de Paiva Júnior}

Doutor em administração pela Universidade Federal de Minas Gerais. Professor do Programa de Pós-Graduação em Administração pela Universidade Federal de Pernambuco. Coordenador do Grupo de Pesquisa Lócus de Investigação em Economia Criativa. Fez mestrado em administração na Universidad de Deusto (Espanha). E-mail: fernando.paivajr@gmail.com. ORCID: 0000-0001-5715-3882 